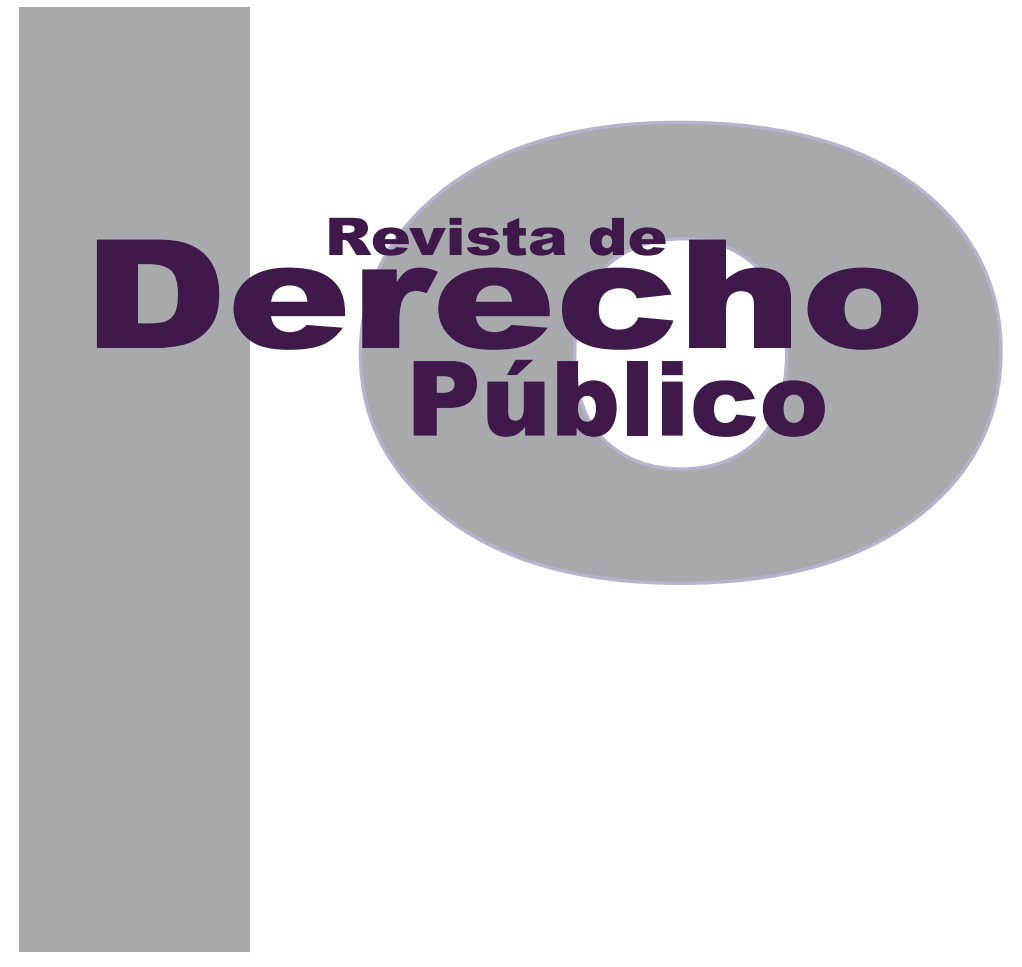

\title{
DIÁlOGO SIN DEBATE: LA PARTICIPACIÓN EN LOS DECRETOS DE LA LEY DE VÍCTIMAS
}

\author{
JULIETA LEMAITRE RIPOLL
}

Universidad de los Andes

Facultad de Derecho

Revista de Derecho Público N. ${ }^{\circ} 31$

Julio - Diciembre de 2013. ISSN 1909-7778 


\title{
Diálogo sin debate: la participación en los decretos de la Ley de Víctimas ${ }^{*}$
}

\author{
Julieta Lemaitre Ripoll**
}

\begin{abstract}
RESUMEN
Este artículo examina la forma como se dio la participación ciudadana en la reglamentación de la Ley de Víctimas (Ley 1448 de 2011) tanto con la población general de víctimas como con las minorías étnicas. A través del estudio de caso de la socialización del Decreto 4800 y la consulta previa de los decretos-ley 4633 (indígenas) y 4635 (afrocolombianos) todos del 2011, el artículo propone una tipología de los diferentes conceptos de participación ciudadana. Estos son: la participación como gobernanza, la participación como derecho y la participación como herramienta de transformación social.
\end{abstract}

ABStraCt
This article examines participation in the adoption of the Reglamentary Decrees of Colombia's 2011 Victim's Law (Law 1448): Decrees 4633 (for indigenous peoples), Decree 4635 (afrocolombians) and general Decree 4800. The article proposes a typology of participation to better understand the tensions at work in this process. It defines three different concepts: participation as governance, participation as a right, and participation as a process of social change. It argues these concepts, and the tensions between them, explain the many difficulties of participation in rulemaking, development and public policy consultation.

Cómo citar este artículo: Lemaitre Ripoll, J. (Diciembre, 2013). Diálogo sin debate: la participación en los decretos de la Ley de Víctimas. Revista de Derecho Público, 31.

Abogada Universidad de los Andes, M. A. Universidad de Nueva York, Doctorado en Derecho Universidad de Harvard. Profesora Asociada, Facultad de Derecho, Universidad de los Andes. Correo: jlemaitr@uniandes.edu.co 
Con ello se aporta al debate necesario sobre las muchas tensiones y dificultades cotidianas de la participación de poblaciones vulnerables en procesos de consulta y socialización de leyes y políticas públicas.

Palabras Clave: derecho a la participación, conceptos de participación, Ley de Víctimas, Ley 1448 de 2011, consulta previa.
KEY WORDS: right to participation, concepts of participation, previous consultation, Victim's Law, Law 1448 of 2011. 


\section{SUMARIO}

Introducción - I. LA ORGANIZACIÓN DE LA PARTICIPACIÓN DE LAS VÍCTIMAS: METODOLOGÍA Y OBJETIVOS DE LOS TALLERES - II. LA PARTICIPACIÓN COMO GOBERNANZA - III. ESCOLLOS EN EL CAMINO DEL “BUEN GOBIERNO" - IV. LA PARTICIPACIÓN COMO DERECHO - V. LAS VOCES DE LA PARTICIPACIÓN - VI. LA PARTICIPACIÓN Y EL PODER - VII. EL RETO DE EMPODERAR - VIII. CIERRE: TODOS JUNTOS - Bibliografía. 
Introducción

"Venimos a hacer un diálogo, no un debate" les dice la funcionaria de mayor rango en la reunión y, por la forma de hablar, de Bogotá. El público al que se dirige son cerca de ochenta personas entre hombres y mujeres de diferentes edades, cuyas ropas y timidez en el espacio denotan su origen rural. Se trata de un grupo heterogéneo convocado por el gobierno nacional a Bogotá para hacer una socialización del decreto reglamentario de la Ley General de Víctimas: es el séptimo taller de este tipo, y congrega gente de Boyacá, Amazonas, Caquetá, Casanare, Guainía, Guaviare, Meta y Vichada.

"Queremos hacer un diálogo constructivo, recibir sus sugerencias, sus inquietudes, pero no con la misma mentalidad que generó el problema, sino con mentalidad abierta", insiste la funcionaria. Está de pie frente a una pantalla enorme donde aparecen los logos de las entidades gubernamentales. Su voz, a pesar del micrófono, se pierde en el auditorio y es difícil saber qué tanto la escuchan las personas invitadas, líderes en su mayoría de diversas organizaciones de base, y qué opinan de la invitación al diálogo "no a un debate." Por lo pronto están ahí por cuenta del gobierno que las ha seleccionado, invitado y pagado pasajes, hotel y viáticos. Están ahí para participar.

Este artículo examina la forma como se dio la participación ciudadana en la reglamentación de la Ley de Víctimas (Ley 1448 de 2011), en el segundo semestre de 2011. Describe con detalle las dinámicas de los talleres de socialización de su decreto general reglamentario (Decreto 4800 de 2011) Ilamado "general". ${ }^{1}$ Además analiza la forma en que se dio la consulta de los decretos-ley para minorías étnicas, en especial el 4633 (indígenas) y el 4635 (afrocolombianos): ¿cómo se dio este proceso en la práctica?, ¿cuál fue el concepto de participación que estructuró los intercambios entre gobierno y víctimas?, ¿cuáles son sus aciertos, errores y limitaciones?

Estas preguntas tienen interés académico, pero también son relevantes para la práctica de las políticas públicas. La participación ciudadana en la elaboración de normas no es un proceso nuevo, sin embargo poco se ha escrito sobre ella en el país, y poco se ha pensado en relación con los procesos de justicia transicional que se implementan hoy. No obstante, esta participación es central tanto para el derecho administrativo como para la defensa de los derechos constitucionales. Además, la consulta previa a minorías étnicas, ordenada y defendida por la Corte Constitucional, presenta en la práctica enormes problemas que requieren un análisis que la relacione con debates más amplios sobre

1 En los considerandos del Decreto 4800 se habla de la importancia de la participación: "se hace necesario crear las condiciones propicias para que las víctimas del conflicto armado interno participen como ciudadanos de manera activa en la recuperación y el ejercicio pleno de sus derechos políticos y económicos, sociales y culturales, en la reconstrucción del tejido social y el fortalecimiento de la institucionalidad del Gobierno Nacional encargada de diseñar, ejecutar o implementar la política pública de atención, asistencia y reparación a las víctimas de que trata el artículo 3 de la Ley 1448 de 2011"; también afirman que el Decreto se realizó con la participación de las víctimas: "con el fin de garantizar la participación de las víctimas, sus organizaciones, representantes de la sociedad civil y entidades territoriales, el Gobierno Nacional activó diversas estrategias que permitieron la recepción de numerosos insumos de retroalimentación para que el decreto reglamentario de la Ley 1448 de 2011 se ajustara a la talla de las necesidades de las víctimas y a las realidades regionales". 
los fines y modos de la participación directa de los ciudadanos en las instancias de gobierno y en los proyectos de desarrollo.

La metodología utilizada en este artículo es la de estudio de caso, en concreto la recolección de suficiente material de diversas fuentes para reconstruir de forma detallada el caso en cuestión: tanto la socialización del Decreto 4800 como la consulta de los decretos-ley 4633 y 4635 de 2011. Entre el material recogido para la reconstrucción es importante mencionar el trabajo de un equipo de tres estudiantes que realizaron sendos diarios de campo sobre algunos de estos procesos fuera de Bogotá (Berrío, 2011; Rubiano, 2011; Vargas, 2011). Además de las observaciones el estudio de caso se basa en entrevistas semiestructuradas y conversaciones informales realizadas por mí o por los estudiantes, a líderes indígenas, afrocolombianos, desplazados y funcionarios públicos, así como en la experiencia como integrante del equipo del Centro de Investigaciones Sociojurídicas (cıus) de la Universidad en la redacción de un borrador de los decretos 4633 y $4635 .^{2}$ El material mencionado se complementó con la creación de un archivo personal de numerosos documentos oficiales que dan cuenta del proceso de participación en la elaboración de los decretos, incluyendo las actas de la consulta indígena y la consulta afro, revisión de prensa y compilación de documentos del gobierno y de las organiza-

2 El equipo, liderado por Eduardo Cifuentes Muñoz, realizó a solicitud del Ministerio de Agricultura un borrador de los decretos-ley. Si bien el borrador no fue aceptado como tal, el proceso nos permitió conocer de cerca la consulta previa que aquí se describe. Es importante aclarar que los productos de la consultoría son confidenciales y no hacen parte de este artículo. ciones involucradas. ${ }^{3}$ Por último, se revisó la incipiente literatura colombiana sobre consulta previa y Ley de Víctimas.

Este artículo describe el desarrollo de los talleres de participación y los analiza a partir de una tipología propia sobre los diferentes conceptos de participación en tensión en el desarrollo del proceso. Estos conceptos son: la participación como gobernanza, la participación como derecho y la participación como herramienta de transformación social. Cada uno de estos se explica y relaciona con las dinámicas de la reglamentación de la Ley 1448, para concluir que el gobierno estructuró los espacios de participación como procesos de gobernanza en los que escuchar la retroalimentación de los afectados por las decisiones gubernamentales se propone como parte del "buen gobierno". Sin embargo, este concepto de participación no es siempre el mismo que tenían las organizaciones sociales, inspiradas en parte en el desarrollo del derecho constitucional a la participación y a la consulta previa (es decir, a ser efectivamente escuchadas), y en parte en una tradición latinoamericana de educación y empoderamiento popular. Esta diferencia explica las tensiones y dificultades que se describen y analizan en los siguientes apartes. 


\section{LA ORGANIZACIÓN DE LA PARTICI- PACIÓN DE LAS VÍCTIMAS: METODO- LOGÍA Y OBJETIVOS DE LOS TALLERES}

"Ustedes tienen conocimiento que nosotros no; combinemos las dos miradas, creemos puntos de encuentro, esta es la oportunidad para construir juntos la ruta", les dice la funcionaria que orientó uno de los talleres de socialización en Bogotá a los representantes de las víctimas. Luego les explica el orden del día: hay siete mesas temáticas, una por cada parte del decreto propuesto por el gobierno. En cada mesa temática hay un facilitador o facilitadora que explicará lo que dice el decreto, y un relator o relatora ("gracias al apoyo de cooperación; no son personas del gobierno, son pagadas por la cooperación") que tomará nota de lo que dicen las personas para que todo quede en la memoria del taller. En cada mesa temática las personas tomarán turnos para hablar; los participantes deben rotar por todas las mesas temáticas: "la idea es que se generen muchas propuestas; es muy importante para nosotros poder recoger esa información." Al día siguiente, los funcionarios presentarán los resultados de las mesas temáticas y se abrirá la discusión de todo el decreto en una plenaria.

El orden del día planteado por la funcionaria incluye la estructura básica de la participación propuesta por el gobierno tanto para la socialización del Decreto 4800 (general) ${ }^{4}$ como para

4 El proceso de consulta a los indígenas, que el Decreto Ley 4633 llama excepcional, es descrito en los considerandos así: "Que de conformidad con el numeral 9 del artículo 12 del decreto 1397 de 1996, la Mesa Permanente de Concertación con los Pueblos y Organizaciones la consulta previa de los decretos-Ley 4633 y 4635: primero una presentación general, seguida de la división del grupo en mesas temáticas más pequeñas cada cual con una persona que hiciera la relatoría de lo sucedido, y para terminar una plenaria donde se presentaban los resultados de las mesas temáticas y se abría una discusión general. También fue parte de todo el proceso el viaje de los participantes a las ciudades, el traslado a sitios de reunión contratados por el gobierno nacional (como hoteles, centros de recreación y centros de reuniones) y el pago de viáticos y transporte. A pesar de la diferencia conceptual entre "consulta" para los representantes de los grupos étnicos y "socialización" para la población general, que se refleja en la forma como se crearon los espacios participativos, la metodología utilizada en las sesiones fue muy similar: presentación general, mesas de trabajo, recolección y sistematización de sugerencias.

El proceso de consulta se organizó desde Presidencia, con un apoyo financiero importante de la cooperación internacional. En todos los talleres la presentación inicial estaba a cargo de funcionarios jóvenes del Ministerio del Interior o de contratistas de este; de dependencias de la Presidencia, principalmente Acción Social (luego Unidad de Víctimas) o de la Unidad de Tierras del Ministerio de Agricultura, quienes a veces eran acompañados por líderes de organizacio-

Indígenas concertó una ruta metodológica excepcional y única para la consulta previa del desarrollo del artículo 205 de la ley 1448 de 2011 , que consistió en la realización de 25 encuentros departamentales, 4 encuentros macro-regionales y un proceso autónomo, que contó con la participación de autoridades, organizaciones y víctimas de los pueblos indígenas." EI Decreto Ley 4635 se limita a describir el proceso de consulta a los afrocolombianos, raizales y palenqueros como "adecuado a la ley". 
nes étnicas, y estos podían tener un mayor papel protagónico según el taller. Esta presencia reflejaba el papel más o menos importante de las diferentes organizaciones indígenas y afrocolombianas en la preparación del proceso de consulta, y no tenía un equivalente en la socialización del decreto general.

Para efecto de la sistematización, a todos los talleres asistían jóvenes que registraban el proceso en computadores portátiles. En principio esta sistematización, en especial la de la socialización del decreto general, permitía informar más adelante a cada uno de los participantes si sus propuestas habían sido aceptadas o no. Y, en los procesos de consulta, el gobierno tenía además la responsabilidad de asegurarse de que quedaran las correspondientes actas, que además debían ir firmadas por los líderes; sin embargo, las actas no siempre reflejan la discusión ni están firmadas por los asistentes.

Los talleres tenían dos razones de ser. La primera, y quizá la más imperiosa, era la necesidad de hacer una consulta previa con los grupos indígenas, afrocolombianos y Rom del país, para evitar que la Ley 1448 fuera declarada inconstitucional. ${ }^{5}$ El artículo 205 de la Ley 1448 prevé, para estos efectos, que el gobierno expediría unos decretos legislativos específicos para las minorías étnicas, y que estos debían ser consultados en un término de seis meses. La segunda razón de ser de este proceso era el interés del

5 Por ejemplo, este fue el caso de la Ley Forestal. Corte Constitucional, C-030 de 2008. gobierno de recibir retroalimentación de las víctimas y aumentar la legitimidad de la ley. ${ }^{6}$

Este proceso, realizado con premura, y documentado detalladamente por los jóvenes en sus computadores, es único en el mundo por lo masivo, por lo rápido y por su enorme impacto. Se trataba de la reglamentación de una ley que afectaría directamente, en un cálculo conservador, a unos 4 millones de colombianos, entre desplazados internos, minorías en confinamiento y otro tipo de víctimas del conflicto armado que vive Colombia desde 1985. Además, involucra una serie de materias de enorme complejidad social y jurídica.

Las dificultades del proceso son difíciles de estimar. En primer lugar, por tratarse de la reglamentación de una ley (Ley 1448 de 2011) exigía algún conocimiento de sus 208 artículos y una gran variedad de temas técnicos en ellos cubiertos, como la definición de víctimas, el acompañamiento en procesos judiciales, las medidas de asistencia, las formas de reparación individual y colectiva, la indemnización, la rehabilitación, la restitución de tierras, las garantías de no-repetición y la creación de una nueva institucionalidad. Los decretos propuestos por el gobierno, y sujetos a consulta, no eran más sencillos: cada decreto contenía entre 123 y 297 artículos, cubriendo temas tan complejos como los mecanismos de registro y censo de los beneficiarios, la planeación estatal, el contenido de las medidas de reparación, las responsabilidades de las instituciones, los programas de

6 Ministerio del Interior. (2011). 
retorno, las diversas vías para la reparación y la indemnización, el diseño del sistema de participación por mesas, y puntos muy específicos como el diseño del sistema de alertas tempranas y los mapas de riesgo o la identificación del sujeto de la reparación colectiva, la articulación con el proceso de justicia y paz, entre otros. ${ }^{7}$ El proceso suponía, por lo menos, algún conocimiento y comprensión de estas normas, y la capacidad de reacción a través de argumentos (de un diálogo sin debate).

Además de complejo, el proceso fue rápido y enorme: en seis meses se realizaron, para el decreto "general" 7 talleres regionales con líderes de víctimas y el mismo número de talleres paralelos con funcionarios de todo nivel; 8 para el decreto indígena, 30 talleres incluyendo 4 macro-regionales y para el decreto de afrocolombianos, por lo menos 16 talleres con la Comisión Consultiva. De forma simultánea se realizaron con el pueblo Rom (gitano) un número de talleres que no conocemos y no son evaluados en este artículo, pero que según el decreto involucró a representantes de todas las casas familiares o kumpañy en Colombia. En resumen, por lo menos 64 talleres en seis meses, con cien personas en promedio cada uno, con dos días de propuestas para cada taller, en diferentes partes del país, sin contar con las reuniones preparatorias de los procesos mismos.

7 El Decreto 4800 (general) tiene 297 artículos; el Decreto 4633 (indígenas) tiene 194; el Decreto 4634 (Rom) 123; el Decreto 4635 (afrocolombianos, palenqueros y raizales) tiene 156 artículos.

8 Asistieron, según el citado documento del Ministerio del Interior, 678 víctimas y 456 representantes de instituciones y autoridades locales (Ministerio del Interior, 2011).
Como resultado de este ejercicio, el gobierno recibió solo para el decreto general 7.229 comentarios y sugerencias distintas. Además, asumió la tarea enorme de sistematizarlos, incluyendo los enviados por los ciudadanos en general a través del espacio virtual abierto temporalmente para este fin: www.leydevictimas.gov.co. El profesionalismo de las consultas y socializaciones estuvo presente en numerosos detalles del proceso y en el espíritu de "buen gobierno" de la agenda del presidente Santos, inspirada en el concepto que se describe en el siguiente aparte.

\section{LA PARTICIPACIÓN COMO GOBERNANZA}

Este concepto gira en torno a la importancia de la participación de las comunidades gobernadas en las políticas que les afectan. Tiene varias fuentes directas y relacionadas tanto del derecho administrativo, donde la participación es parte del funcionamiento de las agencias regulatorias, como del Banco Mundial y otras agencias de desarrollo, donde la participación es parte corriente de la implementación y evaluación de los proyectos. La idea que participar es parte de gobernar bien estuvo presente en todo el proceso de consulta y socialización de los decretos de la Ley de Víctimas.

Cuando salimos del auditorio general para pasar a las mesas temáticas me instalé, con una compañera de la Universidad y unos quince líderes de base, en la mesa temática de protección y no-repetición, considerando que la no-repetición en medio del conflicto es quizá la promesa 
más complicada de esta Ley de Víctimas. Y los líderes que participaban de este taller venían precisamente de la zona donde la guerra no da tregua; una incluso se refiere a sí misma y a sus compañeros como nosotros "los que vivimos la guerra".

La mesa temática está ubicada en el gigantesco vestíbulo del centro de reuniones en el que nos encontramos, debajo de una pantalla plana enorme que muestra cifras y logos permanentemente, y entre la constante circulación del personal del lugar con chalecos, los meseros de los refrigerios, los funcionarios que organizan el evento y los líderes que salen a tomar aire fresco o a fumar. La empresa que coordina el taller se Ilama Logyca y su función son los grandes eventos. El lugar completo representa una nueva Colombia que progresa y deja atrás la guerra. Todo es nuevo, incluso afuera los árboles, pequeños, recién sembrados, recalcan el mensaje que estamos ante un proceso de gobierno eficiente, eficaz y transparente.

La facilitadora de la mesa es muy joven, profesional sin duda, de estrato medio o medio alto. También hay otra mujer, igual de joven, tomando nota de lo que se dice sin alzar la vista de un computador portátil. La facilitadora se presenta como "Camila"9 (sin apellido), trabaja en el Ministerio de Justicia y repite muchas de las explicaciones y advertencias de la funcionaria que habló en la plenaria. La sesión de la mesa durará una hora y cuarto, de manera que en los

9 Los nombres y algunas señas de identificación han sido cambiados para proteger las identidades de los participantes en el taller. siguientes dos días todos debemos haber pasado por todas las mesas, advierte. Nos entrega una hoja verde con la lista impresa de las mesas temáticas, para que cada cual la haga perforar al lado de la mesa a la que ya asistió, como forma de asegurarse de que fue a todas las mesas. Además nos dan tarjetas de cartulina para escribir de forma individual las propuestas que no expongamos verbalmente, y nos piden anotar los datos personales pues nos enviarán las respuestas por correo.

Camila explica las reglas de orden (como escuchar al que habla sin interrumpirlo) y una serie de gestos manuales para facilitar las intervenciones (el puño cerrado cuando se pide la palabra) y "para que no nos gritemos, no nos tenemos que estar gritando ni haciéndonos susshhhh". La mayoría de las personas sentadas son bastante mayores que ella pero Camila les habla con condescendencia, usando la primera persona del plural de tantas maestras de escuela: "pensemos en esos procesos que conocemos, en las buenas prácticas para que las podamos incluir en este documento." Y hace una nueva advertencia: "No se trata de presentar casos particulares. Para los casos particulares habrá otro espacio. Esto es para las propuestas generales".

A pesar de la falta de experiencia de Camila, ya que usualmente esta labor la hace alguien que anima y relaja a los participantes, me parece reconocer lo que está haciendo, o intentando hacer. La participación en procesos de creación de normas tiene una larga historia en el derecho administrativo norteamericano. De hecho, hay 
una cierta versión de la participación que surge precisamente de la necesidad de las agencias gubernamentales de escuchar a los beneficiarios y a los perjudicados por las reglamentaciones que adoptan, que se llama notice and comment rulemaking. En el derecho administrativo norteamericano contiene un procedimiento específico con etapas de publicidad de la reglamentación propuesta, recepción de comentarios y respuestas a estos. ${ }^{10}$ Algo similar, aunque menos desarrollado, existe en el derecho administrativo colombiano, donde los artículos 37 y 38 del Código de Procedimiento Administrativo y de lo Contencioso Administrativo prevén la notificación a terceros previa a la expedición de actos administrativos que puedan afectarlos; además, varias entidades regulatorias, como las Comisiones de Regulación creadas por la Ley 142 de 1994 tienen la práctica general de someter borradores de las regulaciones generales a comentarios por parte de los usuarios, antes de expedirlas de manera definitiva.

El proceso seguido en la socialización de los decretos toma algunos elementos del rulemaking, como la publicidad de la norma seguida de unas formalidades para recepción de comentarios escritos (a través del sitio en la red) y la finalidad de recibir retroalimentación sobre unas normas específicas. Sin embargo no lo es propiamente. El rulemaking se hace con grupos afectados

10 El proceso se conoce como rulemaking y está en la Administrative Procedure Act 5 USC 561 y ss. El caso principal es Vermont Yankee Nuclear Power Corp. vs. Natural Resources Defense Council, donde la Corte Suprema estableció unos estándares mínimos de participación. Para una descripción de los fundamentos de este proceso, ver Stewart (1975). Para una crítica del proceso de participación en la elaboración de reglas, ver Rossi (1997). Agradezco a René Urueña la referencia a esta literatura. por las normas de una agencia gubernamental, a menudo grupos de interés poderosos asesorados por abogados. En cambio en este caso, como denota la actitud condescendiente de las facilitadoras, hay una gran diferencia de clase social entre los "profesionales" del gobierno y los líderes que participan. Por eso la metodología se parece más a formas desarrolladas desde los años setenta del siglo XX para trabajar con personas pobres en proyectos de desarrollo.

Así, la metodología en los talleres era también muy similar a un método de participación en proyectos de desarrollo llamado en inglés beneficiary assessment o evaluación de los beneficiarios (EB) en español (Salman, 1987). La literatura del Banco Mundial describe este modelo como una herramienta cualitativa que permite escuchar a los pobres que son los beneficiarios de una medida concreta, y de manera sistemática permite integrar sus percepciones en los proyectos (Banco Mundial, 2002). Es parte de una serie de métodos de participación, algunos de los cuales se inspiran directamente en la investigación-acción participativa que se describe más adelante en este artículo, pero adaptada a las necesidades de los proyectos de desarrollo; este no es el caso del EB, que está dirigido a recolectar información antes que a mejorar los procesos comunitarios.

El EB utiliza diversos métodos de investigación cualitativa para recoger información, como entrevistas focales. En las entrevistas focales en EB se toma un grupo de 10 o 12 personas y se les pide su opinión sobre temas concretos relacionados con las medidas a evaluar. Los resul- 
tados son sistematizados en bancos de datos creados para ese propósito -el Banco Mundial lo llama "escucha sistemática"- y destaca en su sitio web tanto el impacto positivo de la información que así se recoge como lo barato que resulta recogerla. ${ }^{11}$ Para Paul Francis (2001), sin embargo, se trata del método más problemático utilizado por el Banco: su propósito es claramente extraer información a bajo costo sin que se busque, como en otros métodos propuestos por el mismo Banco, una transformación positiva de los individuos o las comunidades intervenidas.

El EB es uno de varios métodos dentro de un enfoque particular de la participación: la participación ciudadana en proyectos de desarrollo, y en la generación, implementación y seguimiento de políticas públicas, como una forma de gobernanza. Es decir: se comprende la participación como una técnica de gobierno que se enfoca a mantener y aumentar la legitimidad del sistema $y$, por lo tanto, el consentimiento de los gobernados. De hecho, el aumento de los esquemas de participación como buena gobernanza es una tendencia mundial promovida por las organizaciones internacionales de desarrollo, en especial el Banco Mundial, a partir de los años ochenta (Cooke y Kothari, 2001) pero también el Banco Interamericano de Desarrollo (1997).

La participación como buen gobierno fue el correlato de las políticas de ajuste estructural en los países "en vías de desarrollo." Así, con la reducción del papel del Estado como distribuidor

\footnotetext{
11 Disponible en http://siteresources.worldbank.org/INTPSIA/Resources/490023-1121114603600/beneficiary_assessment.pdf
}

de recursos, y el mayor protagonismo del mercado, los espacios de participación ciudadana se convirtieron en algo positivo que reduce los costos de los programas estatales, garantiza una mejor ejecución de los recursos y aumenta su efectividad y sostenibilidad (Gaventa y Barret, 2010)

La participación como gobernanza aparece en una nutrida literatura que considera que la participación ciudadana en diversos aspectos de las políticas públicas es una forma eficiente de gobernar con un Estado reducido a lo "necesario". ${ }^{12}$ Este es un enfoque esencialmente pragmático, que dice evitar las discusiones ideológicas sobre principios e ideales para, una vez establecidos unos nortes generales de justicia y equidad, enfocarse en la solución de problemas prácticos y puntuales. ${ }^{13}$ Dentro de este enfoque pragmático la participación es una buena forma de gobernar por muchas razones, entre las cuales se destacan tres:

a. La participación da información. Para este enfoque es claro que las personas comunes y

12 Un documento guía para aproximarse a esta literatura puede ser el muy citado documento de1996 "The World Bank Participation Sourcebook" o también las políticas actuales del Banco Mundial sobre participación. Algo similar sucede en el BID con el Libro de consulta sobre participación (1997). En derecho se considera un clásico en este sentido el artículo de Michael Dorf y Charles Sabel (A Constitution of Democratic Experimentalism. Columbia Law Review, marzo de 1998), inspirado en la teoría social de Roberto Unger (Democracy Realized, 1998). Otro exponente importante desde el punto de vista del estudio de las políticas públicas es Archon Fung (Empowered Participation, 2004, y Deepening Democracy con Erik Olin Wright, 2003). Estos últimos combinan el empoderamiento de los ciudadanos del común (en cuanto individuos) pero con el fin explícito de mejorar la calidad del gobierno local.

13 Sin embargo, a pesar de que dice evitar tomar una posición política, es por lo general evidente que esta literatura es muy afín a la propuesta de un Estado pequeño y eficiente dentro de una economía de mercado fuerte. 
corrientes que se ven afectadas por las políticas públicas muchas veces conocen hechos que desconocen los gobernantes, o tienen preferencias marcadas que es importante conocer para poder gobernar bien. Además de información concreta, estos espacios son útiles para generar soluciones a problemas concretos.

\section{b. La participación brinda legitimidad al gobier-} no. Los procesos participativos generan consensos que favorecen la gobernabilidad, sea porque las personas se sienten escuchadas y eso legitima al gobierno, sea porque efectivamente el gobierno logra responder a sus necesidades y preferencias concretas. La legitimidad surge también del procedimiento de la participación que, estructurado exitosamente, resulta en una percepción de justicia del proceso que tiene altos réditos en materia de legitimidad (Tyler, 2006).

\section{c. La participación fortalece la transparencia y} rendición de cuentas del gobierno. La participación es un mecanismo útil para reducir la corrupción y la ineficiencia de los funcionarios públicos, pues los espacios de participación se convierten también en espacios de denuncia y control ciudadano. Estas son herramientas importantes por el traslado de recursos y responsabilidades a los gobiernos locales, que aumentan también el interés por la "rendición de cuentas," la "transparencia" y la asociación de los ciudadanos.

d. La participación es eficiente. Los modelos participativos de gobernanza conllevan muy bajos costos. El trabajo de los asistentes es gratis, o con una remuneración simbólica. Incluso en muchos casos los mismos asistentes cubren los gastos de traslado y comida, además de aportar su propio tiempo. Pero la principal ventaja no es esta (y hay cada vez más esquemas que consideran compensar a los participantes) sino la eficiencia que surge de tomar mejores decisiones en menores tiempos.

En el caso de los talleres de víctimas, tanto de la socialización del Decreto 4800 como de la consulta de los decretos-ley, la metodología de plenaria-mesa temática-plenaria, junto con la sistematización de propuestas, parece dirigirse a cumplir con estos objetivos, por cuanto se buscaba que los participantes dieran su opinión sobre las normas (entregando información clave para su adecuado diseño e implementación). También era evidente que todo el proceso quería legitimar el gobierno, y en especial el nuevo sistema de justicia transicional para atender y reparar a las víctimas que aparecería como abierto a escuchar sus propuestas. Y era relativamente eficiente en el gasto, a pesar de cubrir los pagos de transporte y logística; se trataba de un gasto que permitía en poco tiempo tomar mejores medidas, más legítimas, y ahorrar problemas que podrían generar gastos mayores.

El modelo implícito en este concepto de participación es la buena administración de empresas públicas y privadas como ideal a seguir. En él la participación es una herramienta más para lograr los objetivos del "buen gobierno" que, según la Fundación del mismo nombre creada 
por el presidente Santos, consiste en "la gobernabilidad democrática”, "la legitimidad del Estado", "Ios principios de transparencia, equidad, compromiso social, pluralismo y eficacia." En realidad la participación así planteada es especialmente útil para la eficacia, lo cual resuena con las palabras de Santos al clausurar la Fundación al inicio de su gobierno: "el mercado hasta donde sea posible, el Estado hasta donde sea necesario". ${ }^{14} \mathrm{Y}$ la participación vista así combina ambos: la empresa privada se convierte en el modelo de un Estado legítimo y eficiente. ${ }^{15} \mathrm{De}$ hecho, este es el modelo de participación implícito en buena parte de la abundante normatividad sobre la participación en políticas públicas adoptada a partir de la Constitución de 1991, enfocado hacia un gobierno más eficiente y más legítimo. ${ }^{16}$

Vuelvo al taller de socialización. Camila reitera en nuestra mesa temática que "se trata de aportar" y no de "debatir o quejarse." Este lema se repite en los talleres de todo el país, en todos los espacio de socialización o consulta de los decretos de la Ley de Víctimas. El Informe Metodológico que guía el proceso dice claramente que el propósito de estos talleres es que las per-

14 Osorio, Camila. (29 de septiembre de 2010). La fundación Buen Gobierno se traslada a Palacio (y muere). La Silla Vacía; Semana.com. (28 de junio de 2010). La tercera vía de Santos..

15 El actual Plan Nacional de Desarrollo "Prosperidad para todos" (20102014) no es una excepción: enfocado en el "buen gobierno" plantea la participación como uno de los principios rectores de este, junto con la transparencia y la rendición de cuentas.

16 Con algunas excepciones de participación de pobres en programas de desarrollo (Gutiérrez Sanín, 2002) como el Programa de Desarrollo y Paz del Magdalena Medio. Los programas de presupuestos participativos, como los de cultura ciudadana, tienen algunos de estos elementos, pero de forma más débil ya que en general no fortalecen la organización comunitaria. sonas puedan "aportar preguntas, apreciaciones y sugerencias" que luego serán sistematizadas. ${ }^{17}$ ¿Pero qué tipo de participación no permite el debate? Solo la que se enfoca en obtener información específica para mejorar procesos, o simplemente en legitimar el statu quo.

En las consultas étnicas, además, la estricta administración del tiempo, del espacio, de los contenidos y la tecnología de la participación giran en torno a la producción y firma del acta que es parte del proceso de consulta previa. Así, la sesión de consulta empieza con la lectura del orden del día, la explicación de las reglas, y ordena y disciplina a los asistentes sin tregua hasta la firma. ${ }^{18}$ En muchas de las consultas con indígenas se incluye al inicio, en todos los órdenes del día, un "ritual de armonización". Las actas sin embargo no lo describen, tampoco registran lo que difícilmente pueda ser presentado como una propuesta concreta sobre un artículo del proyecto de decreto.

La racionalidad burocrática de esta metodología tiene algunas ventajas. Puede ser eficiente para recoger la información y cumplir con la meta principal de mejorar el decreto, y para cumplir con un proceso en el que las personas se sientan tomadas en cuenta, lo cual legitima al gobierno. Toda la ritualidad del proceso gira en torno a estos fines: la sistematización de las propuestas, tarea titánica, los llamados a evi-

\footnotetext{
17 Ministerio del Interior (2011).

18 El equivalente documental en otros espacios participativos es la lista de asistencia, que luego se usará para probar que efectivamente se socializó. Algunos líderes se niegan a firmarlas porque dicen "no saber para qué se usan".
} 
tar la confrontación y las declaraciones "particulares", la producción y firma del acta en los procesos de consulta, la firma de las listas de asistencia y las filas para recoger el sobre con los viáticos, para recibir el refrigerio, etc.

\section{ESCOLLOS EN EL CAMINO DEL "BUEN GOBIERNO"}

Es abundante la crítica al modelo de la participación como gobernanza que parece inspirar la metodología de participación del gobierno. El grueso de las críticas se concentra en la forma como los gobiernos estructuran espacios participativos que a la vez controlan, limitando la posibilidad de transformación social. Es decir, se critica que se comprenda la participación como una herramienta para gobernar, sin aprovechar el potencial transformador de los espacios y en cambio usándolos para legitimar las relaciones de poder existentes (Cooke y Kothari, 2001).

Las críticas más duras acusan a esta forma de participación de ser un modo de manipulación, llamándola participación "neoliberal” y afirmando que deja de lado incluso la concepción liberal de la justicia procedimental para obligar a las comunidades pobres a competir entre ellas por la atención y condescendencia de los burócratas de turno, convirtiendo a las organizaciones populares en meras contratistas del Estado (Restrepo Botero, 2001; Dagnino E., Olivera A., y Panfichi (2006)).

Los espacios de socialización y consulta de los decretos reglamentarios de la Ley de Víctimas pueden caer con facilidad bajo esta crítica. El gobierno controla este espacio participativo: el lugar, los invitados, la forma misma en que se administra a las personas para conseguir las ansiadas propuestas, pero no les traslada poder ni transforma su condición de subordinación frente a los funcionarios. También hay cierta competencia entre las organizaciones por los recursos y la atención de los burócratas que organizan los espacios participativos, despolitizando la participación.

Por otra parte, también es posible argumentar que el reconocimiento dado a las voces subalternas es ya una forma de traslado de poder y de transformación de la sociedad. Los espacios, a pesar del control del gobierno, permiten el conocimiento de unos líderes con otros y la creación de redes. El tratamiento, fuera de las sutilezas descritas en este artículo, es por lo general digno y respetuoso, y los costos de los viajes fueron asumidos por la cooperación internacional, a solicitud del gobierno. Con algunas excepciones, los participantes parecían, en general, satisfechos con el proceso mismo.

Además es importante aclarar la diferencia entre la presencia del Estado en la socialización del decreto general y en las consultas de los decretos-ley para las minorías étnicas. En el caso de las consultas previas era claro que el gobierno buscaba un interlocutor que tuviera la posibilidad de garantizarle un proceso rápido y que cumpliera con los parámetros de constitucionalidad necesarios. En esta medida estaba dispuesto a conceder poder de organización y de decisión al organismo étnico que legalmen- 
te pudiera ser su contraparte, escogiendo para ello a la Mesa de Concertación en el caso de los indígenas y a la Comisión Consultiva de Alto Nivel en el caso de los afrocolombianos. En especial en la consulta indígena, la deferencia del gobierno con la Mesa de Concertación fue evidente; también existió un traslado de recursos a las organizaciones para que realizaran sus propias consultas y contaran con asesores. Y esto es, sin duda, un cambio en las relaciones de poder existentes, y la metodología de los talleres mismos no pudo ocultar lo que ocurría en un sentido más amplio con las organizaciones étnicas.

A pesar de ello, tanto la socialización del decreto general como la consulta previa de los decretos-ley tienen problemas aún en sus propios términos de participación como buen gobierno. El tema de los decretos es extremadamente técnico, y corresponde a una rama especializada del derecho (la justicia transicional). La mayor parte de los participantes no eran profesionales, y de los profesionales presentes solo algunos eran abogados. Las dificultades de comprensión eran evidentes, y manifestadas incluso de manera directa en algunas reuniones en las que los participantes pidieron asistentes y tiempo para entender las propuestas del gobierno.

Ello apunta a un problema frecuente en la participación como buen gobierno, que es la falta de conocimientos técnicos de la ciudadanía. Este es un tema recurrente en el debate sobre la participación ciudadana en políticas públicas, que va más allá de la posibilidad de acompañar o capacitar a las comunidades. Archon Fung (2004) lo llama la crítica desde el igualitarismo fuerte, según la cual las desigualdades estructurales entre ricos y pobres, desigualdades de dinero, información, tiempo y habilidades son tan fuertes que la participación solo funcionaría de la mano de políticas de redistribución radical. Sin una redistribución que cierre la brecha entre ricos y pobres, los pobres se beneficiarían más de unas agencias reguladoras fuertes que administren programas de asistencia y protección que de espacios participativos que legitiman las distribuciones desiguales de recursos, tiempo y educación. Sin acceso a estos, los pobres en los espacios de participación no tienen mucho más que aportar que el conocimiento detallado de su sufrimiento cotidiano.

En la mesa de la que era facilitadora Camila los asistentes hicieron un enorme esfuerzo por traducir su experiencia personal en propuestas concretas, y aportar como se les pedía. Al hacerlo, estimaban qué creían que sería factible pedirle al gobierno, evitando temas importantes pero intratables, como la falta de aplicación de leyes favorables del pasado. En los espacios participativos de la mesa se reflejaba una tensión frecuente entre los funcionarios públicos, en general jóvenes profesionales, y los líderes comunitarios que usualmente tienen mucha experiencia, y decepciones, con la capacidad y voluntad del Estado para implementar políticas pro-pobres. ${ }^{19}$

Otras formas de realizar los talleres podrían haber sido más productivas para el fin de obtener

19 En muchos talleres los asistentes renunciaban a hacer este esfuerzo y permanecian en silencio. 
información de los asistentes. Por ejemplo, en los talleres paralelos de la Mesa de Organizaciones Afrocolombianas (Antonio, 2013) se iniciaba con un diagnóstico del conflicto armado y los daños que había causado, para luego proponer ideas sobre cómo reparar. El iniciar con el diagnóstico permite a los asistentes hablar sobre lo que sí saben (su experiencia cotidiana) y no sobre lo que no saben (las instituciones de la justicia transicional.)

Incluso el Banco Mundial propone metodologías más adaptadas a personas pobres, metodologías que utilizan medios visuales y acercan el lenguaje a la vida cotidiana de los participantes, y se apoyan en facilitadores con un entrenamiento especial para este tipo de talleres. Estas formas alternas son las más comunes en la literatura sobre participación y desarrollo, que recomienda utilizar herramientas no verbales para recoger información (Chambers, 1992, 2002; Nelson y Wright, 1994; Banco Mundial, 1996). Por lo menos en el tema de desarrollo mucho del conocimiento de las comunidades locales no es verbal, sino práctico, y por lo tanto es difícil de expresar en palabras. Para ello se utilizan técnicas (mapas, imágenes, juegos de roles) para que los participantes de forma efectiva transmitan su conocimiento a los facilitadores. ${ }^{20}$ Estas formas no-verbales también se usan con éxito para reconstruir la memoria de eventos pasados y hacer diagnósticos de las inseguridades presentes, un tema importante cuando se trata de cómo reparar los daños del conflicto armado. ${ }^{21}$

Así, las limitaciones del proceso no correspondían directamente a la falta de experiencia de las personas que lo facilitaban, ni al ser participación "como gobernanza" sino a la metodología misma que no tenía en cuenta el tipo de saberes de los participantes. De hecho todas las consultas y socializaciones a las que asistimos contaron con algunos funcionarios cuya buena voluntad era evidente, e incluso, en el caso de la consulta indígena los facilitadores fueron en parte los mismos líderes indígenas. Sin embargo, es muy difícil forzar la participación verbal y conceptual de personas que por inteligentes y capaces que sean cuentan con escasa escolaridad o escolaridad de baja calidad, como es común entre las víctimas del conflicto armado. La exposición argumentada a la manera occidental requiere un entrenamiento específico que no todos los líderes de base (aunque sí algunos) adquieren sobre la marcha. Pero incluso para los más hábiles en términos de expresión oral, era difícil la producción de propuestas sistematizables en lenguaje jurídico. Así, en la práctica el enorme esfuerzo hecho por el gobierno tuvo una productividad limitada en los mismos talleres, y rindió frutos fue en los espacios en los que las organizaciones, en especial la Mesa de Concertación Indígena, contaban con la asesoría de
20 En este sentido ha sido muy exitoso, por ejemplo, el uso del teatro para construir y validar propuestas legislativas (Boal, A., 1998).
21 Por ejemplo, la Comisión de Memoria Histórica lo ha usado exitosamente para reconstruir el pasado. Ver Grupo de Memoria HistóricaCNRR (2009). 
abogados especializados en justicia transicional (como Rodrigo Uprimny, de Dejusticia).

Pero además de la escasa productividad de los talleres, el proceso general de participar para reglamentar tiene un aspecto incómodo, que es la puesta en escena de un régimen de verdad colectivo del cual queda excluido el sufrimiento individual y grupal de las víctimas, en medio del llamado a aportar sobre el contenido del decreto mismo. El sufrimiento en este proceso quedaba como "un caso particular" o como una intervención que "no contiene un aporte." Y sin embargo, de forma paradójica, es ese el mismo sufrimiento mudo que la Ley de Víctimas espera reparar, y que origina la conceptualización constitucional de la participación en este proceso como un derecho fundamental de las minorías étnicas y un derecho humano de los desplazados. De este tema se ocupa el siguiente aparte.

\section{LA PARTICIPACIÓN COMO DERECHO}

La principal motivación para la participación en la reglamentación de la Ley de Víctimas, y de forma muy clara en el caso de los decretos étnicos, fue de carácter constitucional. La Corte había afirmado en varios foros, y en particular en el caso de la consulta previa, que estaba dispuesta a declarar la inconstitucionalidad de leyes que no cumplieran con los requisitos de la participación como derecho. Y este derecho se convertía en un tema delicado cuando se trataba del derecho a la participación de poblaciones vulnerables, como las minorías étnicas y las víctimas del conflicto. Así, además de ser un espacio de "buen gobierno" los talleres de participación eran una garantía de que se estaba protegiendo el derecho a la participación. ¿Pero este qué quiere decir en la práctica? ¿Quién y cómo representa a las víctimas?

En la mesa temática las doce personas que estaban presentes para participar a nombre de las víctimas eran todas de origen rural, pertenecían a alguna organización, la mayoría de desplazados y dos de indígenas. La mujer que habla con mayor seguridad, "Carmen", revela unos cuarenta años de edad, de tez muy blanca y pelo muy negro, largo y suelto. La persona que habla con mayor timidez, "Armando", es un hombre de unos sesenta años y unas manos inmensas y gastadas que coloca sobre la mesa sin saber qué hacer con ellas. Está también un joven silencioso, de unos veinte años, rasgos indígenas, con una chaqueta de cuero nueva. Los demás intervienen por lo menos dos veces en el tiempo que estamos en sesión, pero por el ruido se oye muy poco. Puedo llevar registro de Carmen porque habla fuerte, y de Armando porque los demás le piden constantemente que repita para poderlo oír.

La Corte Constitucional ha insistido en el derecho de los desplazados y sus organizaciones de participar en las políticas que les afectan; desde la sentencia T-025 de 2004 adoptó este tema y a esta población. ${ }^{22}$ En numerosos autos

\footnotetext{
22 Esto se hizo bajo el liderazgo del entonces magistrado Manuel José Cepeda, quien como consejero para la Constitución en el gobierno de César Gaviria también apoyó la inclusión de mecanismos de democracia directa en la Constitución de 1991.
} 
de seguimiento la Corte ha mencionado este derecho, e incluso generó un indicador de participación para medir la superación del estado de cosas inconstitucional, según el cual se superará dicho estado cuando los desplazados puedan "efectivamente" participar en las decisiones de política pública que les conciernen. ${ }^{23}$ Otros grupos protegidos de la Corte han sido los indígenas y los afrocolombianos. En varias sentencias y en dos grandes autos de seguimiento de la T-025 (004 y 005) la Corte Constitucional ha desarrollado el derecho a la consulta previa de estos pueblos como un derecho fundamental, derecho que se extiende a las normas que los afectan.

Una lectura cuidadosa de las sentencias muestra que en todos estos casos para la Corte Constitucional el derecho a participar, incluido el derecho fundamental a la consulta previa, es un derecho expresivo antes que un derecho a la toma de decisiones, incluso cuando se considera el imperativo del autogobierno. ${ }^{24}$ Aún en el caso de la consulta previa, en el cual se pensaría que debe haber reconocimiento del autogobierno indígena, se trata casi siempre de un

23 En el auto 116 de 13 de mayo de 2008 la Corte Constitucional establece los siguientes indicadores complementarios: escenarios adecuados para participar, condiciones adecuadas para participar, garantías para participar, y una respuesta adecuada por parte de las instituciones a las sugerencias y observaciones. En este sentido el gobierno, Acción Social, a través del Decreto 1997 del 1 enero del 2009 adoptó un protocolo de participación para la población desplazada, y un aplicativo del mismo.

24 Aún en los casos de las minorías étnicas, por lo general de lo que se trata es de que la participación de las comunidades "en la medida de lo posible" sea "clave" en las decisiones que se tomen: T-769 de 2009, T-188 de 1993. En la T-769 se dijo que la consulta debía tender hacia el consentimiento y adoptó los criterios del sistema interamericano diciendo que la consulta es una relación de "comunicación y entendimiento". derecho expresivo. Así por ejemplo, en la sentencia T-129 de 2011 en la que la Corte aclara su jurisprudencia sobre la consulta previa, la define como "un diálogo entre iguales" en el cual los organismos estatales y concesionarios del Estado "puedan explicar de forma concreta y transparente cuáles son los propósitos de la obra y la comunidad pueda exponer cuáles son sus necesidades y puntos de vista frente a la misma." La Corte es reacia a decir que la comunidad puede vetar un proyecto en principio, esto lo ha decidido más bien caso por caso y solo cuando hay una gran afectación del territorio y se puede optar por una conducta "menos lesiva". ${ }^{25}$ Incluso entonces el consentimiento es un fin que se debe buscar, pero no aparece necesariamente como una condición sin la cual no se pueda realizar el proyecto, o en este caso, aprobar el decreto. Es decir que el derecho a participar no es un derecho a decidir, sino a ser escuchado.

La expresión, por lo menos en la definición de la Corte Constitucional, es lo que caracteriza este segundo concepto de la participación como derecho: se trata de ser escuchado, distinto a tener el derecho de decidir. Esto puede estar relacionado con el hecho que la justificación de la participación, y de la consulta previa como una expresión particular de esta, no se finca solamente en el autogobierno. En cambio, la Corte parece considerar la participación de los indí-

25 En los siguientes eventos: cuando la obra implique el traslado o desplazamiento de las comunidades; cuando se trate de almacenamiento o vertimiento de desechos tóxicos en las tierras étnicas o cuando los proyectos tengan un "alto impacto social, cultural y ambiental" en la comunidad que "conlleva a poner en riesgo la existencia de la misma, entre otros". 
genas en cuanto grupo vulnerable, así como de los desplazados, y suponemos, de las víctimas en general, un derecho ligado, como dice en la T-025, al principio pro homine, esto es, a "la interpretación que propenda por el respeto de la dignidad humana." En este sentido, los desplazados tienen derecho a expresar la condición en la que se encuentran y a ser escuchados en la toma de decisiones como parte del respeto a la dignidad humana "sin perjuicio de que las entidades responsables adopten las decisiones sobre el plan de manera autónoma" como dice la Corte una y otra vez. Así, en varios autos de seguimiento a la sentencia T-025 la Corte ordenó el diseño de mecanismos de participación de los desplazados en las políticas que les afectan, y definió que uno de los veinte derechos mínimos indicadores de la superación del estado de cosas inconstitucional es su participación “de manera oportuna, significativa y efectiva en la adopción de las decisiones estatales que les interesan y los afectan". ${ }^{26}$

Esta participación expresiva, ligada a la dignidad humana, es especialmente relevante para las víctimas. Demuestra el reconocimiento de que es uno de los objetivos de los programas de reparación (De Greiff, 2008). Esta es la línea, por ejemplo, que adopta la Fundación Social en el documento que entregó como insumo en el proceso de creación de la Ley de Víctimas, al afirmar que la participación de las víctimas "y el reconocimiento de su sufrimiento" son centrales para el proceso (Zamora y Gaviria, 2011).

26 Auto 008 de 26 de enero de 2009. El Auto 383 de 2010 señaló las múltiples deficiencias de este sistema de participación.
Por supuesto que la defensa de la dignidad humana no agota la genealogía de la participación como derecho. La relación más usual es fincar el derecho a participar en la tradición colonial del cabildo abierto, como espacio creado por los gobiernos para escuchar las quejas y reclamos ciudadanos. También tiene una fuerte presencia en las revoluciones liberales del siglo XVIII y XIX, donde la participación directa de los diversos estamentos sociales y la representación política iban de la mano. Una genealogía más reciente tiene que ver también con su formulación al interior de las redes transnacionales de derechos humanos como central a la realización de los derechos, y estos, a su vez, como centrales para el desarrollo. ${ }^{27}$ En estos conceptos la participación como derecho no surge de la dignidad humana sino de la identidad ciudadana. ${ }^{28}$ Sin embargo, en la presentación actual del derecho a participar en el derecho colombiano, esta genealogía ligada a la ciudadanía se invoca más para fundamentar los mecanismos de la democracia representativa y los de los espacios reglados de la democracia directa que la consulta previa.

En general, cuando se trata de la participación de ciudadanos en espacios poco reglados la

27 IED (2010) describe el rol de la participación en el indicador PANEL en Naciones Unidas, así como la influencia de los enfoques de desarrollo y derechos humanos expuestos por Amartya Sen. Pero ver la crítica de Peter Uvin (2004) argumentando que la incorporación de los derechos humanos no cambia las estructuras de poder.

28 Por lo general es un derecho humano de los ciudadanos, o modelado sobre el ideal de ciudadano, lo cual implica unos estándares básicos para el sujeto que participa, en particular el ser capaz de seguir unas reglas fundamentales de deliberación. En general este uso de argumentos resulta en la puesta en escena de una identidad eurocéntrica. 
Corte Constitucional ha tendido a fundar el derecho en la dignidad humana antes que en el autogobierno ciudadano. En Colombia este es el concepto de participación como derecho que la Corte Constitucional ha adoptado en su jurisprudencia, de forma implícita o explícita, al sustentar los ideales democráticos de autogobierno y definición amplia de la dignidad humana. ${ }^{29} \mathrm{Y}$ es, antes que la eficiencia, la dignidad humana la que llama a participar, así no se trate de espacios de toma de decisiones.

En el concepto de la participación como derecho humano, esta se define como un bien social en sí mismo, importante para el derecho constitucional y los derechos humanos, por lo menos por tres razones:

a. La inclusión política: la participación en políticas públicas es un derecho que permite la expresión de experiencias, necesidades, preferencias e intereses, en particular de grupos e individuos que usualmente están excluidos de la toma de decisiones porque carecen de poder político y económico. Sin la participación quedan silenciadas las voces de muchos ciudadanos, y queda silenciada no solo la expresión de sus intereses y preferencias, sino, lo que es más grave, la expresión de su sufrimiento y de las violaciones a su dignidad humana.

29 En términos de filosofía del derecho, esta visión es acorde con las referencias hechas por la Corte a autores como Dworkin, Rawls y Sen. Sin embargo otros autores presentan visiones más completas de la participación como derecho, en particular Iris Young. También es muy relevante el libro de Judith Shklar, Rostros de la injusticia (Faces of Injustice, 1988) así como el de Upendra Baxi (1985), Taking Suffering Seriously: Social Action Litigation in the Supreme Court of India. b. La justicia: en segundo lugar, la participación es una obligación, un imperativo moral del Estado. Es requerida por el tipo de justicia que está implícita en un Estado social de derecho: el sistema constitucional colombiano implica la justicia como la distribución de unos bienes sociales primarios. Este criterio de justicia (que es darle a cada quien lo que “le corresponde") necesariamente está incompleto si no existe la posibilidad de escuchar a aquellos ciudadanos que manifiestan que son víctimas de injusticia en dicha distribución (Shklar, 1988). Si bien ello no implica que el Estado va a distribuir los bienes sociales de acuerdo con todos los reclamos, si requiere que se les escuche antes de decidir cómo hacer la distribución.

c. El autogobierno: por último, la participación como derecho materializa la posibilidad del autogobierno. La filosofía política ha señalado los muchos límites de la democracia exclusivamente electoral para realizar el ideal de democracia. Varios sistemas de gobierno conservan formas antiguas de democracia directa - por ejemplo en los cantones en Suiza o algunas municipalidades del noreste de Estados Unidos-, considerando que está más cerca del ideal de autogobierno que fundamenta a las democracias liberales.

Es importante insistir en que el derecho a participar, en principio, no está contemplado en CoIombia como un derecho a decidir. Son pocos los espacios decisorios de la participación directa. La Ley 134 de 1994 que estableció las formas de la democracia participativa lo hizo dentro de 
la lista del artículo 103 constitucional, siendo: la iniciativa popular legislativa y normativa; el referendo; la consulta popular del orden nacional, departamental, distrital, municipal y local; la revocatoria del mandato; el plebiscito y el cabildo abierto. ${ }^{30}$ La interpretación de la Corte Constitucional no deja de lado otras formas de participación directa, pero sí limita a estos casos las instancias de participación donde los ciudadanos toman decisiones ${ }^{31}$ (SU-747 de 1998).

La Corte diferencia dos momentos de la democracia participativa: la toma de decisiones, "altamente institucionalizada" y el control del poder público, "sujeto a la dinámica social" (C929 de 2003). Además, justifica el aumento de los espacios participativos en la Constitución de 1991 como un mecanismo para legitimar la creciente actividad estatal, haciendo eco de la tendencia mundial al aumento de los mecanismos de participación de la mano de la capacidad regulatoria de las agencias estatales.

A pesar de contemplar pocos espacios decisorios, la Corte le da un alto contenido simbólico a la participación porque permite a los ciudadanos expresar sus necesidades, deseos e intereses, y a la comunidad política deliberar sobre cuándo estos son verdaderos derechos exigibles. Es el derecho “madre" el que permite a las

30 Un proyecto de ley estatutaria que cursa en el Congreso reemplazaría esta normativa e incluye nuevas instituciones como son: la rendición de cuentas, las veedurías ciudadanas (hoy reglamentadas por su propia ley), los acuerdos participativos y las alianzas para la prosperidad, así como una institucionalidad y recursos al servicio de la participación ciudadana. (Congreso de la República, 12 de junio de 2012).

Gutiérrez Sanín (2002) hace un detallado análisis que muestra que la democracia participativa en Colombia es consultiva y no decisoria. personas tener voz en una democracia. ${ }^{32}$ Aun así la Corte es reacia a darle poder decisorio a estas instancias menos regladas, considerando que el principio de la participación es "el interés general" y que a menudo estas son instancias de expresión de los intereses privados (C-891 de 2002). Queda entonces claro que el derecho a la participación se da para la Corte en el contexto de un Estado que escucha, escucha cuyo valor es fuertemente simbólico, ya que en todo caso las autoridades conservan el poder de decidir "de manera autónoma" y en aras de proteger "el interés general".

De cierta forma se puede decir que los talleres, como fueron estructurados, cumplían con garantizar el derecho a la participación. Tanto en la socialización del decreto general como en la consulta de los decretos étnicos el gobierno invirtió mucho para garantizar que las víctimas pudieran decir lo que pensaban del texto propuesto de los decretos, e incluso para sistematizar los comentarios de manera que fueran un insumo en la elaboración del decreto final. Sin embargo esta garantía no deja de ser problemática.

\section{LAS VOCES DE LA PARTICIPACIÓN}

En los espacios destinados para garantizar el derecho a participar en cuanto derecho a ser escuchado, no es claro qué es lo que se está es-

\footnotetext{
32 La Corte dice que la participación ciudadana "Comporta una revaloración y un dimensionamiento vigoroso del concepto de ciudadano y un replanteamiento de su papel en la vida nacional" (C-180 de 1994). Este replanteamiento implica la participación permanente "en los procesos decisorios no electorales que incidirán significativamente en el rumbo de su vida." Llama a la participación "el principio fundante del Estado" y el "fin esencial de su actividad" (C-103 de 1996).
} 
cuchando. Las voces de las víctimas se deben limitar, por razones de tiempo, de recursos y de la motivación misma del proceso, a comentar sobre los artículos legales y no a expresar sus preocupaciones o a hablar de sus experiencias. Como lo dicen a menudo los funcionarios, lo que se espera de ellas son "propuestas concretas." En esta parte del artículo, entonces, se hace una descripción detallada de cómo funcionan las "voces de la participación" y de los filtros para la escucha que el mismo método del taller crea.

En la mesa temática, por ejemplo, después de una exposición de 25 minutos de la joven funcionaria, quedaron solo 45 minutos para la discusión; los asistentes intentan producir propuestas para el tema de "no-repetición." Se enfocan en el reclutamiento de niños, que como aclara Camila no está en la propuesta de Decreto, pero es un tema que los anima: "A mí me preocupa que habiendo batallón en (x) Guaviare se estén llevando a los niños...". Alguien agrega: “Se los están llevando en todas partes y nadie hace nada." Proponen comités, inversión social, educación, internados para niños en riesgo, albergues para familias huyendo del reclutamiento... Y ellos mismos desestiman la factibilidad de sus propuestas: "eso ya se hace y no funciona..." es una frase que oigo varias veces. De ahí pasan a otro tema que Camila no había mencionado: el desminado. "Sin desminado no hay retorno" explica alguien de manera categórica; los demás asienten ante lo obvio. ${ }^{33}$ La joven del computador teclea animada todas estas propuestas.

33 Sin embargo, en el Decreto 4800 fuera de la participación del Programa Presidencial para la Acción Integral contra Minas Antipersonal, en varios comités no se menciona el desminado...
Súbitamente, Armando, el hombre mayor, pide la palabra. "Yo soy padre de cinco hijos" empieza "y tengo uno discapacitado y no lo puedo dejar solo, y la niña no puede estudiar porque tiene que estarlo cuidando, y no me dan la droga siempre y si no la hay le dan ataques y cae en el suelo y no sabemos qué hacer." Sigue el relato conmovedor, pero es interrumpido por Camila quien le señala con firmeza que ese no es el espacio para los temas particulares, que por la tarde lo habrá y pueden hacer fila y hablar con una persona de Acción Social que le ayudará a ver cómo está su situación con el seguro y cómo hacer para tener acceso a la droga. Armando entiende y se calla, con expresión de que tenía algo más que contar. Una de las asistentes trata de salvar su dignidad abstrayendo de la intervención el que eso le pasa a muchos desplazados, que no les dan la droga, pero el tema no tiene eco.

Así, el método de participación, planteado como ejercicio del derecho a participar, excluye en la práctica las manifestaciones personales de dolor y el diagnóstico que hacen de la situación. Tanto “lo particular”, al decir de los funcionarios, como el diagnóstico, no solo están bajo el manto de la sospecha de ser o no versiones ciertas, sino que además no son la verdad que se les pide produzcan: la verdad sobre el funcionamiento correcto del Estado en las mencionadas "propuestas". Es decir, las voces de las víctimas que el derecho a participar garantiza quedan, en las notas de la reunión descrita, silenciadas.

A los asistentes se les pide no solo abstraerse de sus circunstancias personales, sino de lo que 
saben sobre los límites del derecho y las instituciones que operan en los territorios en que viven, donde la violencia y el conflicto están tan imbricados en la fábrica social que determinan los espacios y dinámicas de la sociabilidad (Das, 2006, Lemaitre, 2011). Se les pide de muchas formas que no hablen de lo que saben, y que en cambio se expresen en un lenguaje que sea comprensible para la joven que teclea la memoria de "las propuestas".

Es posible que el diagnóstico propio y la expresión del sufrimiento individual se den, pero en otros espacios por fuera o incluso anteriores a los participativos. En el caso de los decretos-ley 4633 y 4635 existieron reuniones y espacios paralelos a los talleres de participación como el que se describe en este artículo. Y en esos casos el enorme trabajo organizacional detrás de la elaboración de esta consulta permite suponer que en los múltiples espacios "propios" (algunos durante la misma consulta pero sin la presencia de delegados del gobierno) se realizó tanto el diagnóstico como la expresión del sufrimiento. Y quizá, de alguna manera, el gobierno estaba escuchando.

La pregunta que queda abierta, entonces, es una interrogante por la justicia que funda el derecho a la participación, la justicia como la escucha del dolor del otro: ¿exige el derecho a la participación que el Estado escuche más allá de las propuestas concretas?, ¿se puede ejercer en todos los espacios llamados participativos?, ¿cuándo se convierten las limitaciones propias del espacio de interacción con el Estado en limitaciones del derecho a participar? Todas estas son preguntas difíciles que no se resuelven con el llamado judicial a escuchar a los que se sienten víctimas de una injusticia, como elemento esencial para tomar decisiones justas.

A la socialización del decreto general acudieron funcionarios especializados en atender casos “particulares", pertenecientes a la nueva institucionalidad del entonces recién creado Departamento para la Prosperidad Social, pero por lo general venían de la anterior "Acción Social". Se ubicaban en mesas con computadores y sillas dispuestas para la atención individual a las personas con consultas concretas sobre sus derechos. Ante ellos se formaron largas colas, las mismas que vimos en el lugar donde debieron recoger los "viáticos" (dinero en efectivo en un sobre cerrado) para cubrir los gastos adicionales del viaje.

Las filas para recibir atención individual tienen una explicación práctica, pero también presentan un problema en términos de participación. Para una cierta visión de la participación, esta permite que las personas excluidas de una sociedad sean parte de un proceso de aprendizaje y transformación que les posibilita "adquirir conciencia de las estructuras de opresión que configuraban sus vidas", conciencia que les facilitaría su superación (Gaventa y Barret, 2010). Y una forma probada de generar esta conciencia es, precisamente, en la escucha de los casos individuales, en compartir el sufrimiento para sacar en grupo conclusiones sobre el origen estructural de este sufrimiento, y solo a partir de dicho diagnóstico entender cómo transformar las estructuras que lo causan. El separar la participación de la expe- 
riencia individual es entonces una forma, en esta tradición, de evitar que se den las condiciones de transformación que la misma proclama del derecho a la participación promete...

\section{LA PARTICIPACIÓN Y EL PODER}

Una parte importante de la literatura sobre participación, en particular la disciplina de ciencia política y antropología política, la concibe como una forma de movilización ciudadana. Lo que busca es trasladar efectivamente el poder de decidir sobre lo público, de los actores que usualmente lo controlan a las personas del común, por lo general excluidas del poder social y económico. Pero no es solo un traslado del poder de decisión, es también una escuela de formación y transformación democrática donde las personas excluidas adquieren conciencia de las circunstancias estructurales de opresión, así como recursos materiales y simbólicos para cambiarlas. En este sentido los espacios de participación se estructuran para facilitar la formación de ciudadanos con la capacidad para retar los poderes establecidos y así cambiar el mundo social. A menudo, pero no siempre, va de la mano de otras expresiones como pueden ser diversas formas de protesta social (marchas, manifestaciones artísticas, piquetes, cabildo abierto, huelga, paro, carteles, etc.). La participación es pues una forma de movilización social, pero es también un medio para convocar a las personas a movilizarse por sus intereses y necesidades, para conocerlas, articularlas, unirlas a otros en situaciones similares, y lograr un verdadero poder para cambiar la sociedad.
En Sur América esta idea de participación surge en los años 1960 y 1970 con una gran diversidad de experiencias de enfoques participativos para la transformación social. Su pensador más reconocido es Paulo Freire, quien propuso una forma de alfabetización de adultos que al mismo tiempo generaba procesos profundos de empoderamiento y transformación social (la conocida "pedagogía de los oprimidos"). Por esta época la teología de la liberación, con su opción preferencial por los pobres, propició la formación de comunidades eclesiales de base a través de las cuales la Iglesia Católica apoyaba la organización, creación de conciencia, autoayuda y resistencia al poder de las personas pobres. En Colombia el gran exponente de esta corriente fue Orlando Fals Borda, quien junto con los intelectuales del grupo Ilamado Rosca de Investigación Acción Social incorporaron una propuesta transformativa a la investigación, propuesta que es también la de Alain Touraine, sociólogo francés bastante influyente en toda la región. La teología de la liberación, como la pedagogía de los oprimidos y la investigación-acción participativa alimentaron muchas variaciones en el mismo sentido, como "la filosofía de la liberación", "el arte de la liberación”, "el teatro de los oprimidos" y, quizá su variante más persistente en la región, la llamada educación popular. Esta es una forma de trabajo de organizaciones no gubernamentales en la región comprometidas con la transformación social.

En Colombia la participación como transformación social ha tenido varios experimentos de largo alcance, algunos promovidos desde el mismo Estado. El gran ejemplo es el de las Juntas 
de Acción Comunal o JAC (Peña, 2010; Gutiérrez Sanin, 2002). En el modelo de las JAC, liderado en su momento también por Orlando Fals Borda, el Estado promovía la definición de los pobladores marginales de las ciudades como personas capaces e inteligentes, y a partir de esta premisa se les delegaba poder para decidir de forma autónoma e independiente sobre una serie de aspectos de sus barrios. ${ }^{34}$ Así, decidían sobre el gasto de algunos recursos, y tomaban decisiones sobre escuelas, restaurantes escolares, prácticas de saneamiento y en especial sobre la construcción y mejora de viviendas y de espacio público. Eventualmente se han visto afectadas por la corrupción, la fragmentación y la cooptación por los partidos políticos, pero no sin antes haber jugado un papel central en la construcción de las grandes ciudades.

Las JAC no son el único ejemplo de la participación como transformación social acogida y promovida desde el mismo Estado. La Asociación Nacional de Usuarios Campesinos (ANUC) es otro ejemplo de un proceso que, como las JAc, implicó una transformación a gran escala a partir de la participación comunitaria (Zamosc, 1983). La ANUC fue creada por el gobierno de Carlos Lleras Restrepo (1966-1970) para organizar la demanda de tierra para la reforma agraria, y como tal lideró procesos de redistribución de tierras y de protesta campesina. Otro experimento más reciente es el Programa de Paz y Desarrollo del

34 En 1959 Jorge Gaitán Cortés define a estas comunidades como compuestas por "seres capaces, inteligentes, de una extraordinaria ingeniosidad, a quienes nos empeñamos en no permitir que hagan su aporte de esfuerzo para solucionar sus propios problemas y en no facilitar que gobiernen sus propias comunidades locales." Citado en Peña, 2010, p. 199.
Magdalena Medio que concierta programas con organizaciones de base que manejan recursos y protagonizan su propio desarrollo. También están los presupuestos participativos, donde los ciudadanos votan en qué quieren que se inviertan los recursos estatales y las Asambleas Constituyentes departamentales y municipales que funcionan como órganos de control y de toma de decisiones en los espacios locales, en especial para establecer directrices de inversión y desarrollo (García, 2005.)

Todos estos espacios de participación se caracterizan porque permiten la transformación social a través de la agregación de intereses individuales en la toma de decisiones directas sobre el bien de la comunidad. Parten de la confianza en las capacidades de las personas del común y en el potencial transformador de los espacios de participación para lograr una sociedad más justa e incluyente. La participación como movilización es un espacio igualitario, transformativo y de empoderamiento:

a. Espacios igualitarios: en primer lugar la participación es deseable en cuanto es un espacio o proceso igualitario pues parte de la base que todas las personas tienen la misma capacidad y derecho para expresar lo que sienten y piensan, y que son igualmente dignas y capaces de hacerlo. El espacio igualitario implica un ethos igualitario que suspenda las diferencias en jerarquías entre las personas que participan.

b. Transformación social: en segundo lugar, los espacios de participación se plantean como 
generadores de transformaciones individuales, grupales y sociales positivas. Esta transformación consiste esencialmente en la generación de la conciencia de pertenecer a un grupo social con problemas similares, y la comprensión de la situación de este grupo al interior de la sociedad en general. Es un conocimiento que permite y propicia la acción política, y por eso es movilizadora. También incluye otras transformaciones deseables, como la educación y sensibilización de los funcionarios frente a los derechos humanos y el surgimiento de liderazgos al interior del grupo de ciudadanos.

c. Empoderamiento: en tercer lugar el espacio participativo es un espacio de empoderamiento, pero empoderamiento en un sentido particular de este concepto (pues el concepto de la participación como gobernanza incluye su propia versión de empoderamiento). En el sentido transformador, el empoderamiento quiere decir que el grupo que participa adquiere poder político a través de la participación. Es un poder real de toma de decisiones, exigencia de presentación de cuentas, e incluso de redistribución de recursos que se espera pase del Gobierno a las organizaciones de base. Esto tiene un sentido y una finalidad democrática: que las personas comunes y corrientes adquieran y ejerzan poder real frente al gobierno. ${ }^{35} \mathrm{Al}$ mismo tiem-

35 Si bien en los otros dos conceptos se habla de poder, tiene implicaciones distintas. En la participación como gobernanza el "empoderamiento" se refiere a que las personas comunes y corrientes sean capaces de gestionar soluciones a sus propios problemas en lugar de esperar asistencia externa. En la participación como derecho el acceso al poder está bastante reglado, de manera que es en realidad de forma po, no se trata del poder por el poder, o del mero cambio de los individuos o grupos en el poder, sino de un poder que transforme las circunstancias estructurales que mantienen a unos grupos excluidos y oprimidos.

El modelo de empoderamiento se nutre de la visión liberal-radical, socialista y populista de la ciudadanía, parte intrínseca de la historia de la democracia liberal, capturada a menudo en la frase "la voz del pueblo es la voz de Dios." Implica una visión de los sujetos de la participación como grupo o grupos sociales que deberían tener el poder en una democracia, y que si no lo tienen es por injusticia. Así, usualmente nos referimos al "pueblo" para hablar precisamente de las mayorías excluidas del gobierno y de las promesas de justicia de la democracia liberal. Y la historia de las democracias son diversos intentos por lograr llevar al poder al "pueblo" o por mantener su exclusión real con mecanismos de inclusión formal. Además de buscar una materialización efectiva del "gobierno del pueblo" la participación como movilización se extiende a otros grupos.

También considera que la participación en políticas públicas debe llevar a un mayor poder real de diversos colectivos históricamente excluidos. Generalmente esos son los mismos sujetos colectivos a los que la Corte ha respondido con su doctrina del enfoque diferencial: las mujeres,

excepcional que los colectivos sociales pueden intervenir en la toma directa de decisiones en políticas públicas y el empoderamiento se refiere al poder de hablar y ser escuchado, no de tomar decisiones. En cambio, el empoderamiento de la participación como transformación social implica la redistribución del poder y de los recursos hacia los grupos (no solo los líderes) sociales. 
los discapacitados, los indigentes, los indígenas, los afrocolombianos, los niños y niñas... Así, por ejemplo, un feminismo que abogue por la participación como movilización consideraría que las mujeres son las que deben tener el control de las políticas públicas que las afectan como grupo (y no solamente "ser escuchadas"). En resumen, la clave de este concepto es que la participación como movilización es la participación directa en la toma de decisiones de políticas públicas para transformar las circunstancias estructurales.

Existen varias propuestas de análisis que consideran este concepto de participación como el más valioso en términos de democracias y de justicia. Así por ejemplo, tres escalas bien conocidas de la participación asumen que este es el tipo de participación que está "al final de la escalera" (Arnstein, 1969) o en el grado más alto (White, 1996) o como resultado de la aplicación del "cubo de poder" para el análisis (Gaventa, 2006; Arnstein, 1969). ${ }^{36}$ Gaventa y Barret (2010) resumen los fines de la participación como: construir confianza y autoestima entre sus participantes, cambiar las prioridades de desarrollo, cambiar la actitud de los servidores públicos, aumentar la capacidad de la sociedad civil, llevar a cambios de política y, a fin de cuentas, propiciar la justicia social. ${ }^{37}$

36 White (1996) hace una escala de participación que va de la meramente nominal a la transformadora. Este es el mismo sentido de la escalera de Arnstein (1969). Algunos ejemplos de cómo la participación alcanza el potencial transformador están en Hickey y Mohan (2008) así como en Cornwall y Gaventa (2001); Goetz y Gaventa (2001) explican cómo pasar de usuarios y consumidores a agentes activos con responsabilidades.

Esto abre la puerta a otra serie de debates según los cuales la participación no sirve para cumplir estos fines. La opinión de Gaventa y

\section{EL RETO DE EMPODERAR}

¿Fue el proceso de socialización y consulta de los decretos de la Ley de Víctimas un proceso de empoderamiento en este sentido? En un sentido inmediato no lo fue: el objetivo era avalar rápidamente los decretos, y no se tuvo ni el tiempo ni la intención de hacer un proceso que fortaleciera las organizaciones de base o socializara el poder estatal. Hacerlo, además, supera la voluntad de los funcionarios y requiere un rediseño de las instituciones mismas; como se ha visto, las veces que se ha dado en Colombia, como con las JAL y la ANUC, requiere una institucionalidad especial.

No se trata solo de la real renuencia y falta de preparación de los funcionarios en este tipo de participación. Si además no hay cambios en los diseños institucionales de responsabilidad y toma de decisiones, y esta sigue reposando en los funcionarios públicos, estos difícilmente le apostarán a trasladar la toma de decisiones a la comunidad. Máxime cuando la responsabilidad disciplinaria y penal por estas sigue residiendo en los funcionarios. Así, replantear la participación en el sentido de subir la "escalera" propuesta por Arnstein (1969) o el cubo de participación de Gaventa y Barret (2010) (en la cual hay cada vez más poder de los ciudadanos) requiere unos cambios radicales en el diseño de las instituciones mismas como los estudiados por Fung (2004) y Fung y Wright (2003), otros

Barret (2010) es que sí, pero antes ha habido críticas importantes, v. gr. Mansuri y Rao (2004). 
proponentes de la democracia "profunda" (Santos, 2004; Unger, 1998; Fals Borda, 1998).

Además, persisten múltiples obstáculos y dudas sobre este tipo de participación. Estas dudas reflejan críticas que se han hecho en la literatura a la participación en general. Apenas a una década de haberse incluido la participación en los programas de desarrollo surgió una crítica vigorosa de la receta global (Cooke y Kothari, 2001; Mosse, 1996; Stirrat y Henkel, 1997; Gujit y Shah, 1998; Cornwall, 1998). También surgió una literatura que insiste en la necesidad de que la participación realmente transforme, en lugar de legitimar, las relaciones de poder existentes (White, 1996; Hickey y Mohan, 2004; Gaventa 2006, Gaventa y Barret, 2010). Más allá de las críticas y recetas, ha habido poca literatura que evalúe si la participación de cualquier tipo efectivamente transforma o no la sociedad. Un meta-análisis reciente de estudios de caso de participación (Gaventa y Barret, 2010) dice que sí hay efectos positivos, pero señala un "25\%" de efectos negativos de los procesos sin importar si su intención es o no de transformación social.

Algunos de los efectos negativos de la participación "realmente existente" están relacionados con disputas por los recursos escasos. Este es, por ejemplo, el problema de la destinación de recursos de los pobres para la participación. Participar, más allá de dar un simple voto, requiere que las personas destinen recursos propios. En la literatura de desarrollo esto se reconoce como "la transferencia de los costos a los beneficiarios" (Cooke y Kothary, 2001; Mosse,
1996; Stirrat y Henkel, 1997). Otro ejemplo es la agudización de los conflictos entre organizaciones comunitarias y al interior mismo de las organizaciones que compiten por recursos. $Y$ está también la posibilidad de captura de las organizaciones populares por intereses privados que proveen recursos, incluyendo las redes de clientela políticas.

En Colombia quizá el problema que más se menciona en la práctica se refiere a la posibilidad de la representación de las comunidades involucradas: a menudo los funcionarios e incluso muchos líderes y activistas de ong presentan dudas "privadas" sobre los procesos participativos como el de la Ley de Víctimas y de su capacidad de efectivamente lograr mayor justicia social. Se trata de problemas de representación (quién habla por quién, con qué mandato, qué hace que una comunidad lo sea "en realidad" o dónde radica la autenticidad que le permite hablar a nombre de un grupo) y de calidad de la intervención (es conocimiento especializado, de profesionales, requiere abstraer y generalizar, etc.).

Además, hay una larga lista de obstáculos a la posibilidad de una participación emancipadora promovida desde el gobierno mismo para que las comunidades puedan decidir de forma directa sobre los asuntos que las afectan. El primer obstáculo se refiere a los tiempos disponibles para participar. Los tiempos de la participación que empodera son muy distintos a los tiempos de las políticas públicas que requieren de la participación. Allí rara vez hay tiempo para que las personas comprendan las propuestas, las discu- 
tan en grupo, generen confianza los unos en los otros y en sus líderes, capaciten líderes, acuerden responsabilidades grupales e individuales, así como planes de acción y redes de confianza. Todos estos procesos requieren mucho tiempo, sin mencionar incluso el tiempo requerido para el desarrollo de una conciencia política sobre las propias circunstancias (v. gr. Hailey, 2001).

El segundo obstáculo tiene que ver con las dinámicas de los grupos humanos y la forma como afectan la toma grupal de decisiones. Las personas en grupos pueden tomar decisiones muy malas. Cooke y Kothari (2001) mencionan las tendencias estudiadas de los grupos a tomar riesgos injustificados y a escoger las opciones que tienen el menor número de enemigos, la tendencia a desestimar los intereses de las personas que no pertenecen al grupo y la vulnerabilidad a la presión.

El tercer obstáculo tiene que ver con la posibilidad de las comunidades oprimidas y excluidas de articular una voz propia que refleje intereses propios y entendibles para el Estado. La participación requiere que los ciudadanos, y las organizaciones, hablen por sí mismas de forma que resulten inteligibles para la formulación de políticas públicas, es decir, para los funcionarios estatales. Para resumirlo, en estos espacios se espera que las personas actúen y hablen articulando de forma clara cuál es su sufrimiento y cómo resolverlo dentro de los parámetros del Estado. Esto demanda la producción de una subjetividad, y una voz, que es por tradición una voz occidental, con algo de educación formal, quizá masculina, y probablemente de clase me- dia, subjetividades lejanas de la vida rural de la mayoría de las víctimas, sean o no minorías étnicas, mujeres, niños y niñas y discapacitados.

Esta exigencia de inteligibilidad y autenticidad es problemática en muchos sentidos. En primer lugar está el problema de la autenticidad cuando hay diferencias culturales importantes, y en especial cuando el que se espera que sea autónomo ocupa un lugar subalterno en la sociedad. La exigencia de autenticidad puede ser una forma de control sobre los grupos subalternos, y algunos autores han señalado que los mecanismos participativos se pueden convertir en formas de vigilancia y control de los pobres (Kothari, 2001). Para Henkel y Stirrat (2001) la exigencia de la participación obliga a las personas a poner en escena identidades modernas que los hagan unos buenos sujetos de los procesos de desarrollo. También como proceso puede ocultar las desigualdades de poder al interior de los grupos, así como los comportamientos inapropiados y las motivaciones egoístas de las personas que participan a nombre de comunidades subalternas.

Un ejemplo de lo problemática que es la exigencia de autenticidad es la demanda de que los indígenas participen como sujetos morales democráticos y ecológicos. Ello niega la humanidad de los indígenas, con todas sus falencias y debilidades humanas, y se rehúsa a enfrentar la posibilidad de una destrucción violenta de individuos y culturas de los que se espera a toda costa que hablen con una voz auténtica (Lemaitre, 2009). Existen además muchos ejemplos de la forma como los procesos de participación pueden ser ciegos a las dinámicas de poder al 
interior de las organizaciones, por ejemplo, con la frecuente exclusión de las mujeres y de otros intereses minoritarios (Gujit y Shah, 1998; Cornwall, 1998).

Otro tipo de obstáculo a la participación comunitaria es el hecho indiscutible de que en Colombia el liderazgo a nivel comunitario hace más vulnerables a la violencia a los líderes que se animan a participar. Son hechos cotidianos las amenazas y actos de violencia, incluso asesinatos, de los líderes llamados a participar en los procesos de la Ley de Víctimas. De una forma bastante contundente el precio por la justicia transicional "sin transición", es decir, en medio del conflicto, lo pagan los líderes sociales.

A pesar de todos estos problemas, algunas organizaciones lograron obtener más poder a través del proceso de reglamentación de la Ley de Víctimas. Este fue el caso de la Mesa de Concertación Indígena, donde se reunían las principales organizaciones nacionales (Rodríguez y Orduz, 2012; Brilman, 2013). La Mesa de Concertación supo hábilmente contar con el apoyo del gobierno para hacer la consulta del decreto, y se la jugó por respaldar el decreto en los procesos de todo el país. Con ello los líderes que estaban en la Mesa lograron superar sus diferencias internas para presentar un frente unido ante el gobierno y ante las bases, y surtir un proceso que además sirvió para legitimarlos con miras a las próximas elecciones internas. Las discusiones internas se mantuvieron a puerta cerrada, y la aparente pasividad en los talleres públicos parece haber sido el resultado de una actitud de confianza en los líderes y en la Mesa, tanto como de discusiones que se habían dado en espacios privados.

El caso de los afrocolombianos fue distinto. La Comisión Consultiva de Alto Nivel (en adelante la Consultiva) en principio debía jugar el mismo papel entre la comunidad afrocolombiana que la Mesa de Concertación Indígena. Pero la Consultiva desde su conformación había tenido problemas de legitimidad y credibilidad con sectores amplios del movimiento afrocolombiano, incluyendo muchos consejos comunitarios y organizaciones urbanas de base destacadas. Al saber que la consulta del Decreto Ley sería manejada por la Consultiva, un grupo amplio de organizaciones reclamaron para sí el ser los interlocutores legítimos y consiguieron financiación para su propio proceso de creación y consulta de un decreto reglamentario. Sin embargo, el decreto que finalmente fue adoptado fue el consultado a través de la Consultiva, profundizando la división interna y dando pie a acusaciones mutuas de falta de legitimidad y representación. Por otra parte, también dio pie a nuevos procesos de reorganización de las comunidades negras, y a la promoción por parte de estas de un instrumento que permita la consulta del sujeto colectivo afrocolombiano (Antonio, 2013). En esta medida se puede hablar de transmisión de poder y de transformación social como efecto inesperado de una participación que en su inicio se plantea como simple gobernanza.

Ambos casos tienen en común, sin embargo, el uso por parte de las organizaciones no solo de los espacios formales como el taller que se describe en este artículo, sino de los intercambios 
informales con el gobierno y entre los líderes, responsables de buena parte de este empoderamiento. En ambos espacios, formales e informales, con el tiempo se fueron forjando relaciones de confianza entre algunos de los funcionarios públicos de nivel medio y los líderes sociales, así como entre los líderes de base y los activistas de las ong y entre estos y la densa red de profesionales que gira en torno al tema. Estos profesionales, además, rotan entre diversos puestos en organizaciones, gobierno y administradores de la cooperación internacional, manteniendo vivas las relaciones de confianza mutua y credibilidad que les permiten tener influencia en las decisiones de política. Puede que esta no sea la participación a la que se refiere el concepto de participación como transformación social, pero sí se trata de un proceso de influencia en la toma estatal de decisiones, y de un traslado de poder y recursos a las organizaciones étnicas.

\section{CIERRE: TODOS JUNTOS}

En la mesa temática, Camila indica que esta será la última intervención y que es el momento de ir a la siguiente mesa, que cada cual puede escoger qué mesa quiere. Carmen dice: "pero quedémonos todos juntos, ¿a cuál vamos?” Y varios asienten. El grupo se mueve como grupo hacia la siguiente mesa. Se crean, quién sabe, nuevas solidaridades y conciencia de grupo. Nadie se despide de Camila que está hablando con la funcionaria que presentó el evento en la plenaria inicial. La joven del computador sigue tecleando, absorta, no sé si en la memoria o en otro texto.
Estos talleres de socialización/consulta son, en el mejor de los casos, formas más o menos eficientes de recoger información y de aumentar la legitimidad del gobierno y la transparencia de su proceso de toma de decisiones. Es decir, aspiran a cumplir el proyecto de la participación como forma de gobierno. Sin embargo, potencialmente podrían ser mucho más: podrían ser espacios de expresión y crecimiento de las víctimas en las cuales se ensayan modelos de autogobierno y se exploran formas de relación más igualitarias entre ellas y con las autoridades, esto es, podrían garantizar el derecho a ser escuchado de formas más profundas y honestas que los talleres descritos; podrían ser un proceso transformativo que se multiplicara a través de estos líderes, en el cual se incluyeran instituciones que trasladaran el poder a los ciudadanos; finalmente, podrían materializar la participación como transformación social.

En realidad los diversos conceptos de participación son complementarios y tienen la posibilidad de enriquecerse mutuamente generando círculos virtuosos. Así, el poder de las organizaciones y de los ciudadanos les puede hacer más transparentes, eficientes e informados, lo cual a su vez facilita los objetivos del "buen gobierno" y, por supuesto, permite la garantía de los derechos. Difícilmente se dará una administración eficiente, eficaz y legítima de una transformación social radical, como la que traza la Ley de Víctimas, sin contar con una ciudadanía empoderada y capaz, lo cual pasa por supuesto por resolver las circunstancias más angustiosas de la pobreza. Además, difícilmente se harán realidad las órdenes de la Corte sin una admi- 
nistración pública eficiente, eficaz y, sobre todo, legítima.

Se puede pensar que esta propuesta es utópica y que no tiene en cuenta las circunstancias reales de violencia y miseria, de lucha por recursos y de falta de confianza que se vive en las zonas rurales donde persiste el conflicto, y en los barrios a donde llegan los refugiados con el conflicto, y el miedo, a cuestas. Esto es sin duda cierto. Pero al mismo tiempo no deja de existir la posibilidad de cambio de estas circunstancias a través de la transformación de las prácticas cotidianas, y la creación de espacios de participación es, también, la posibilidad de hacerlo. Y este ejercicio inicial del gobierno debería mostrarle que es capaz de hacerlo, y lo que es más importante, que es capaz de hacerlo de una mejor forma.

Por lo pronto, con independencia de las intenciones del gobierno, los fondos gastados en hacer los talleres por todo el país sirvieron a un propósito paralelo al de generar los "aportes" y el "diálogo sin debate" buscado por las facilitadoras. Los líderes se encontraron, se identificaron los unos a los otros, crearon en algunos casos relaciones iniciales de confianza mutua, y aprendieron un poco más sobre el nuevo aparato del Estado que surge a la sombra de la Ley de Víctimas. Estos contactos y esta información pueden ser inocuos, pero también pueden gestar la improbable pero necesaria movilización de una conciencia cívica que le dé impulso a la superación real del conflicto armado, cosa que difícilmente sucederá de la sola mano del Estado y de la Ley.
Bibliografía

Antonio Rosero, E. (Diciembre, 2013). Consultando el sujeto colectivo. Revista de Derecho Público, 31.

Arnstein, Sherry R. (July, 1969). A Ladder of Citizen Participation. JAIP, 35 (4), 216-224.

Banco Interamericano de Desarrollo. (1967). El Libro de consulta sobre participación del BID. Washington: BID.

Banco Mundial. (2002). Empowerment and Poverty Reduction: a source book. Washington: World Bank.

Banco Mundial. (1996). The World Bank participation Sourcebook. Washington: The World Bank.

Bank Information Center -BIC. (2000). Cómo poner en práctica la participación en el Banco Interamericano de Desarrollo. Washington: BIC.

Baxi, U. (1985). Taking Suffering Seriously: Social Action Litigation in the Supreme Court of India. Third World Legal Studies, vol. 4.

Berrío, J. (2011). Diario de campo consulta macrorregional de Occidente. Cali, 11 y 12 de noviembre de 2011.

Boal, A. (1998). Legislative Theater Using Performance to Make Politics. Londres: Routledge. 
Brilman, M. C. (Diciembre, 2013). La mesa permanente de concertación con los pueblos y organizaciones indígenas. El diálogo que es su propio fin. Revista de Derecho Público, 31

Chambers, R. (1997). Rural Appraisal: Rapid, Relaxed and Participatory. IDS Discussion Paper, 311. Brighton: IDS.

Chambers, R. (2002). Participatory Workshops. A Sourcebook of 21 Sets of Ideas and Activities. London: Earthscan.

Colombia. Congreso de la República. (Junio, 2012). Informe de conciliación al proyecto de Ley Estatutaria número 227 de 2012, Senado 134 de 2011, Cámara Acumulado con el 133 de 2011. Gaceta del Congreso, martes 12 de junio de 2012.

Colombia. Ministerio del Interior. (2011). Informe metodológico de la socialización del Decreto General de la Ley de Víctimas. [Fotocopia].

Cooke, B. y Kothari, U. (2001). Participation: the New Tyranny? London: Zed Books.

Cornwall, A. (1998). In my own Back Yard: Participatory Wellbeing Assessment in Suburban Britain. Social Change, 28 (2/3), 17-40.

Cornwall, A. (July, 2008). Unpacking Participation: Models, Meanings and Practices. Community Development Journal, 43 (3), 269- 283.

Cornwall, A. y Gaventa, J. (October, 2001). From Users and Choosers to Shapers and Makers:
Repositioning Participation in Social Policy. IDS Bulletin, 31.

Dagnino, E., Olvera, A. y Panfichi, A. (2006). La disputa por la construcción democrática en América Latina. México: CIESAS.

Das, V. (2006). Life and Words: Violence and the Descent to the Ordinary. Berkeley: University of California Press.

De Greiff, P. (2008). Justicia y reparaciones. En C. Díaz (ed.). Reparaciones para las víctimas de la violencia política. Bogotá: ıcтנ.

Dorf, M. y Sabel, Ch. (March, 1998). A Constitution of Democratic Experimentalism. Columbia Law Review, 98 (2).

Estados Unidos de América. Administrative Procedure Act 5 USC 561.

Estados Unidos de América. Corte Suprema. (1978). Vermont Yankee Nuclear Power Corp. vs. Natural Resources Defense Council, 35 U.S. 519.

Fals Borda, O. (1998). Participación Popular. Bogotá: IEPRI, Universidad Nacional.

Francis, P. (2001). Participatory Development at the World Bank. En B. Cooke y U. Kothari. Participation: the New Tyranny? London: Zed Books.

Fung, A. (2004). Empowered Participation Reinventing Urban Democracy. Princeton: Princeton University Press. 
Fung, A. y Wright, E. O. (2003). Deepening Democracy. London: Verso.

García-Villegas, M. (2005). Sociedad de emergencia: acción colectiva y violencia en Colombia. Bogotá: Defensoría del Pueblo.

Gaventa, J. (November, 2006). Finding the Spaces for Change a Power Analysis. IDS Bulletin, 37 (6).

Gaventa, J. y Barret, G. (2010). So what Difference does it make, Mapping the Outcomes of Citizen Engagement. IDS Working Paper, 247.

Goetz, A. M. y Gaventa, J. (2001). From Consultation to Influence: Bringing Citizen Voice and Client Focus into Service Delivery. IDS Working Paper, 138. Brighton: IDS.

Comisión de Memoria Histórica -CNRR. (2009). Caja de Herramientas para recordar y narrar el conflicto. Bogotá.

Guijt, I. y Shah, M. (Eds.). (1998). The Myth of Community: Gender Issues in Participatory Development. London: Intermediate Technology Publications.

Gutiérrez Sanín, F. (2002). Participación ciudadana y pobreza en Colombia. Bogotá: Misión para el diseño de una estrategia para la reducción de la pobreza y la desigualdad (MERPD).

Hailey, J. (2001). Beyond the Formulaic: Process and Practice in South Asian NGo. En B. Cooke y U. Kothari (Eds.). Participation: the new tyranny? London: Zed Books.
Henkel, H. y Stirrat, R. (2001). Participation as Spiritual Duty; Empowerment as Secular Subjection. En: B. Cooke y U. Kothari (Eds.). Participation the New Tyranny? London: Zed Books.

Hickey, S. y Mohan, G. (2008). Participation from Tyranny to Transformation. London: Zed Books.

Kothari, U. (2001). Power Knowledge and Social Control in Participatory Development. En B. Cooke y U. Kothari (Eds.). Participation: the New Tyranny? London: Zed Books.

Lemaitre, J. (2009). El derecho como conjuro. Bogotá: Siglo del Hombre y Ediciones Uniandes.

Lemaitre, J. (2011). Constitución o barbarie. En C. Rodríguez (Ed.). Retos al derecho en América Latina. Buenos Aires: Siglo XXI.

Mansuri, G. y Rao, V. (2004). Community Based (and Driven) Development a Critical Review. World Bank Research Observer, 19 (1).

Mosse, D. (1996). The Ideology and Politics of Community Participation Tank-irrigation DeveIopment in Colonial and Contemporary Tamil Nadu. In R. D. Grillo and R. L. Stirrat (eds.). Discourse of Development: anthropological perspectives, pp. 255-291. Oxford: Berg.

Nelson, N. y Wright, S. (Eds.). (1994). Power and Participatory Development: Theory and Practice. London: IT Publications. 
Osorio, C. (29 de septiembre de 2010). La fundación Buen Gobierno se traslada a Palacio (y muere). La Silla Vacía.

Peña, M. L. (2010). El programa cınva y la acción comunal. Construyendo ciudad a través de la participación comunitaria. Bogotá: Universidad Nacional.

Restrepo Botero, D. I. (Julio-septiembre, 2001). Eslabones y precipicios entre participación y democracia. Revista Mexicana de Sociología, LXIII (3).

Rodríguez, C. y Orduz, N. (2012). La consulta previa: dilemas y soluciones. Bogotá: Dejusticia.

Rossi, J. (1997). Participation Run Amok: The Costs of Mass Participation for Deliberative Agency Decisionmaking. Northwestern University Law Review, 92 (1).

Rubiano, S. (2011). Diario de campo consulta macrorregional del Decreto 4633. Bogotá. [Manuscrito].

Santos, B. de. (2004). Democratizar la democracia: los caminos de la democracia participativa. México: Fondo de Cultura Económica.

Semana.com. (28 de junio de 2010). La tercera vía de Santos. Recuperado dehttp://www. semana.com/politica/articulo/la-tercera-viasantos/118654-3

Sen, A. (1999). Development as Freedom. Oxford: Oxford University Press.
Shklar, J. (1988). Faces of Injustice. Yale: Yale University Press.

Stewart, R. B. (June, 1975). The Reformation of American Administrative Law. Harvard Law Review, 88 (8).

Stirrat, R. y Henkel H. (November, 1997). The Development Gift: The Problem of Reciprocity in the ngo World the annals of the American Academy of Political and Social Science, 554, 66-80,

Touraine, A. (1981). The Voice and the Eye: An analysis of Social Movements. Cambridge: Cambridge University Press.

Tyler, T. (2006). Why People Obey the Law. Princeton: Princeton University Press.

Unger, R. (1998). Democracy Realized. Londres: Verso.

Uvin, P. (2004). Human Rights and Development. Bloomesfield: Kumarian Press.

Vargas, J. (2011). Socialización del Decreto 4800 con víctimas. Cali. [Manuscrito].

White, S. (1996). Depoliticizing development: the uses and abuses of participation. Development in Practice, 6 (1), 6-15.

Young, I. M. (1990). Justice and the Politics of Difference. Princeton: Princeton University Press. 
Zamora, A. y Gaviria, P. (2011). Participación de Zamosc, L. (1983). Los usuarios campesinos y las víctimas en el marco de la Ley 1448 de las luchas por la tierra en los años 70. Bogotá: 2011 o Ley de Víctimas. Bogotá: Fundación Cinep.

Social. 